\title{
LOW COST POWDER METAL TURBINE COMPONENTS
}

\author{
A. Banik, Special Metals Corporation, Princeton, KY \\ K. A. Green, Rolls-Royce Corporation, Indianapolis, IN \\ M. C. Hardy, Rolls-Royce plc, Derby, U.K. \\ D. P. Mourer, GE Aircraft Engines, Lynn, MA \\ T. Reay, Ladish Co., Inc., Cudahy, WI
}

Keywords: Powder Metal, Rene 88, RR1000, Forging

\begin{abstract}
Driving down processing costs on military and commercial aerospace components is an unending quest for the process metallurgist. Concurrently, the integrity of the powder metal (PM) component must be maintained or improved in these high strength, high temperature, fatigue limited components. A unique processing route, slightly subsolidus hot isostatic pressing (SSHIP) combined with press conversion operations has provided an alternative process route for PM processing of turbine disk materials. The SSHIP + press conversion process route provides the potential for new thermomechanical processing routes for turbine disks, rings and seal components.
\end{abstract}

Under funding from the AFRL Metals Affordability Initiative, a modified powder metallurgy process route has been investigated to reduce the processing costs and logistics problems associated with specialized equipment for the conversion of highly alloyed superalloy forging billet. An Advanced Integrated Process Team (AIPT) consisting of General Electric Aircraft Engines, RollsRoyce Corporation, Ladish Co., Inc. and Special Metals Corporation utilized task driven program management tools in the application of this technology for production turbine components. In this paper, the transformation from laboratory studies using production alloys to turbine disk property results will be presented. The evaluations demonstrated that the SSHIP + conventional press forging process route provides a technically feasible alternative process route for advanced turbine component hardware.

\section{BACKGROUND}

Toll gate criteria was established by the AIPT at critical junctures of the program in order to monitor progress and provide a means to measure success of the program activities. To assure the process route was pervasive, two highly alloyed PM nickel base alloys were evaluated. One alloy, Rene 88, representing a low solvus, high refractory type alloy is presently utilized by General Electric in the turbine section of a broad spectrum of military and commercial aircraft. Conversely, the second alloy, RR1000, is in the early phases of production implementation at Rolls-Royce and represents a high solvus, lower refractory alloy. The Rene 88 alloy utilizes a superplastic forging route for disk production with a post forging heat treatment to obtain a defect tolerant microstructure. The higher solvus alloy, RR1000, provides increased strength at elevated temperatures by utilizing a controlled forging and heat treat practice to produce a finer grain, post heat treat microstructure. The nominal composition of the two alloys is presented in Table I.
Table I Production alloy compositions were utilized.

\begin{tabular}{|l|c|c|c|c|c|c|}
\hline Alloy (wt. \%) & $\mathrm{Cr}$ & $\mathrm{Co}$ & $\mathrm{Mo}$ & $\mathrm{W}$ & $\mathrm{Nb}$ & $\mathrm{Ti}$ \\
\hline Rene 88 & 16.0 & 13.0 & 4.0 & 4.0 & 0.7 & 3.7 \\
\hline & $\mathrm{Al}$ & $\mathrm{Hf}$ & $\mathrm{Ta}$ & $\mathrm{Ni}$ & \multicolumn{2}{|c|}{ Minor } \\
\hline & 2.1 & - & - & Bal. & \multicolumn{2}{c|}{$\mathrm{C}, \mathrm{B}, \mathrm{Zr}$} \\
\hline RR1000 & $\mathrm{Cr}$ & $\mathrm{Co}$ & $\mathrm{Mo}$ & $\mathrm{W}$ & $\mathrm{Nb}$ & $\mathrm{Ti}$ \\
\hline & 15.0 & 18.5 & 5.0 & - & - & 3.6 \\
\hline & $\mathrm{Al}$ & $\mathrm{Hf}$ & $\mathrm{Ta}$ & & \multicolumn{2}{|c|}{ Minor } \\
\hline & 3.0 & 0.5 & 2.0 & Bal. & \multicolumn{2}{c|}{$\mathrm{C}, \mathrm{B}, \mathrm{Zr}}$, \\
\hline
\end{tabular}

\section{EXPERIMENTAL PROCEDURE}

The program was structured to pass through multiple Task Gate review points, which divided the experiment into several phases including business case and system integration review, process feasibility stage, production demonstration and systems integration. The process feasibility and production demonstration phases will be reviewed in this paper. The structured approach allowed initial evaluations of the Rene 88 material and application of the identified process refinements into evaluations on the RR1000 alloy.

The standard production process for powder metal alloys consists of conventional argon atomization in conjunction with a hot compaction plus extrusion process operation for billet materials. The compaction plus extrusion operation requires specialized tooling and high tonnage equipment in order to obtain the high extrusion ratios currently required. The extrusion operation provides an axisymmetric strain profile that refines the microstructure for high-resolution ultrasonic inspection as well as permitting super-plastic forging.

Under standard press conversion operations, billet material is processed using a series of redundant working operations to develop a uniform fine grain microstructure. As a result, the strain profile and heat transfer effects are significantly different ${ }^{1}$ when compared to the two-step compact plus extrude sequence. High strain rate tensile testing was performed on as-SSHIP material to assess the ductility of the material under routine press conversion operations. Historical production experience has shown that alloys with minimum ductilities of $25 \%$ can be press converted without substantial surface cracking and material losses. As indicated in Figure 1, the Rene 88 material exhibited tensile ductilities in the range of $25-35 \%$ and was suitable for normal conversion operations. The RR1000 material however, exhibited a significantly lower ductility and ranged from $15-25 \%$ ductility. In order to simulate the normal redundant working operations in press conversion, subscale samples were reduced 
$30 \%$ by rolling and tested. After $30 \%$ reduction, the ductilities had increased significantly. This indicated a potential benefit of an upset operation prior to press conversion that might be required for RR1000 material.

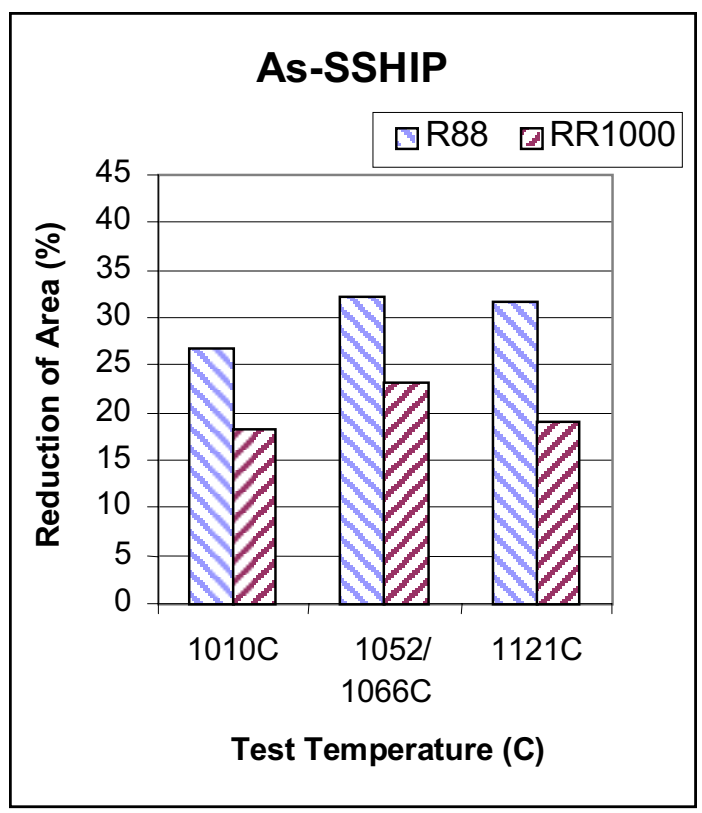

(a)

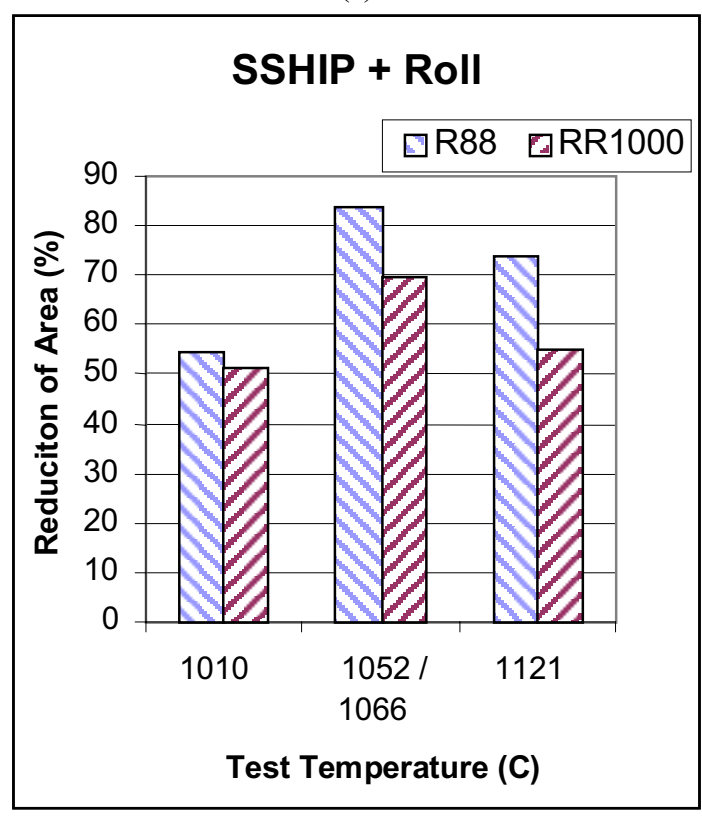

(b)

Figure 1. (a) High strain rate tensile ductilities of Rene 88 and RR1000 following consolidation. (b) Tensile ductilities of both alloys increased significantly with a $30 \%$ roll reduction.

A compression test matrix was established to develop a database for DEFORM ${ }^{\circledR}$ modeling activities. Finite element modeling (FEM) was utilized to assure uniform strain was imparted through the cross-section of the billet during conversion. Press conversion operations are computer integrated with the billet manipulators to control the rotation, bite and draft as the billet traverses across the tooling as indicated in Figure 2.

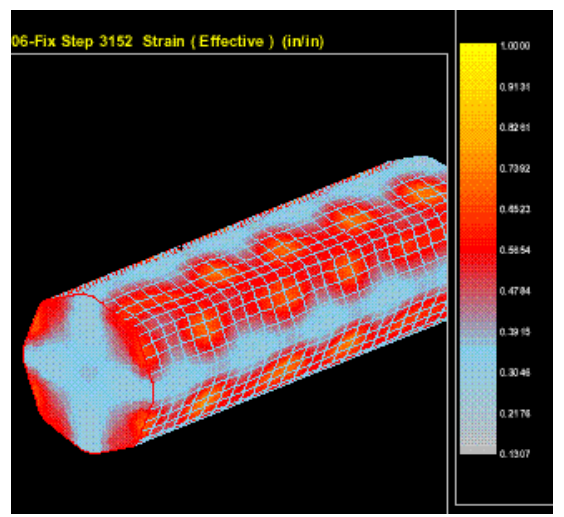

a) FEM for temperature

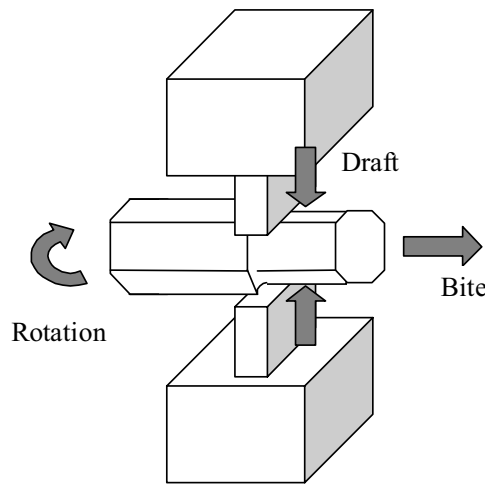

b) press programming

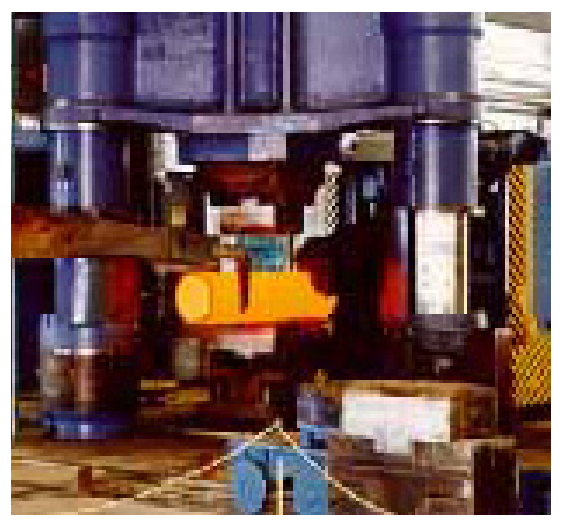

c) billet conversion

Figure 2 Computer integrated press controls facilitates transition of FEM results (temperature / strain profiles) into production programs and conversion operations.

Full-scale powder compacts were produced from each alloy. Each billet, nominally 22" diameter x 2,250 KG was slightly sub-solidus hot isostatically pressed ${ }^{2}$ in the range of 1200 $1250^{\circ} \mathrm{C}$. Billet conversion operations were performed successfully with no evidence of significant cracking or forging defects. After billet conversion, metallographic and nondestructive testing were performed to assess the metallurgical integrity of the billet. The as converted grains size for both the Rene 88 and the RR1000 material averaged ASTM 10 and finer. 
As indicated in Figure 3, initial conversion operations on the Rene 88 material resulted in a fine grain microstructure with residual coarse areas of gamma prime and isolated coarser grains of ASTM 7-8. The RR1000 material converted at slightly higher temperatures exhibited a more uniform microstructure of ASTM 12.

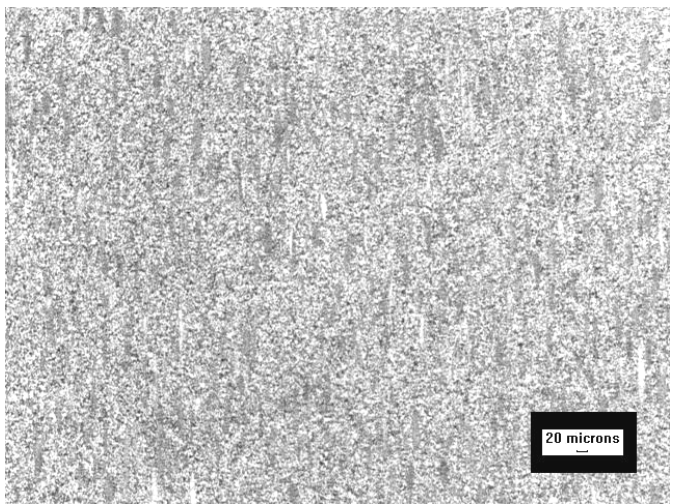

(a) Rene 88 Billet Microstructure

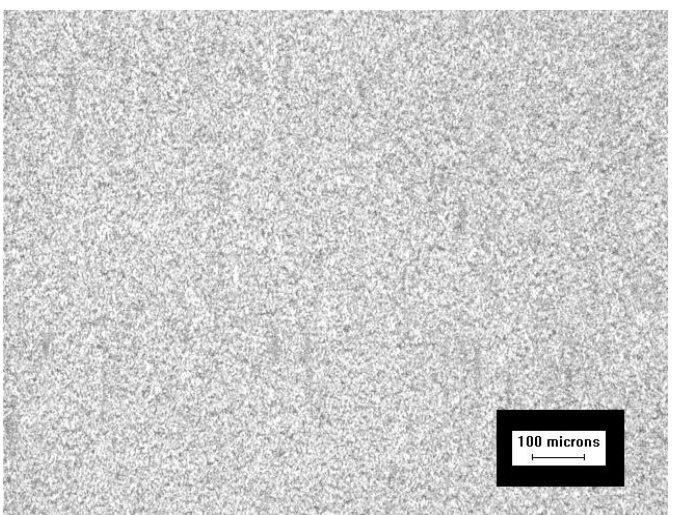

(b) RR1000 Billet Microstructure

Figure 3. The Rene 88 (a) and RR1000 (b) billet microstructures were uniform fine grain.

Ultrasonic inspection was performed on the billet material using a $0.040 \mathrm{~cm}$ flat bottom hole standard. One extremity of the Rene 88 billet exhibited higher noise levels (approximately 25 - 30\% of screen height) which appeared remnant of the billet conversion operation. Conversion operations were modified on the RR1000 material and the billet ultrasonic response was uniform with an average noise level in the range $8-10 \%$ screen height (approximately $12 \%$ of a No. $1 \mathrm{FBH}$ ).

One billet from each alloy was isothermally forged into a turbine disk configuration at Ladish Co, Inc., Cudahy, WI. The Rene 88 material was forged to a Low-Pressure Turbine Disk configuration. The RR1000 alloy was forged into a Turbine Rim Coverplate forging. The disk forgings were heat treated to specification requirements.

\section{RESULTS AND DISCUSSION}

The Rene 88 disk forging revealed a uniform ASTM 6.8 ALA 4.6 microstructure as indicated in Figure 4, typical for this type of thermal/mechanical processing. The specialized heat treatment, which provides the defect tolerance characteristics of the alloy, can result in localized areas of critical grain growth. The disk was macroetch inspected after heat treatment and did not exhibit any areas of critical grain growth (CCG) or other unusual features. This is a key finding of the program since CGG arises when non-uniformly strained areas ${ }^{3}$ are exposed to the solution temperature. The change from extrusion to press conversion was expected to impart a significantly different strain profile in the initial billet. In addition to the macroetch response of the component, exposure on test blanks from the raw forging also did not produce any abnormal grain growth.

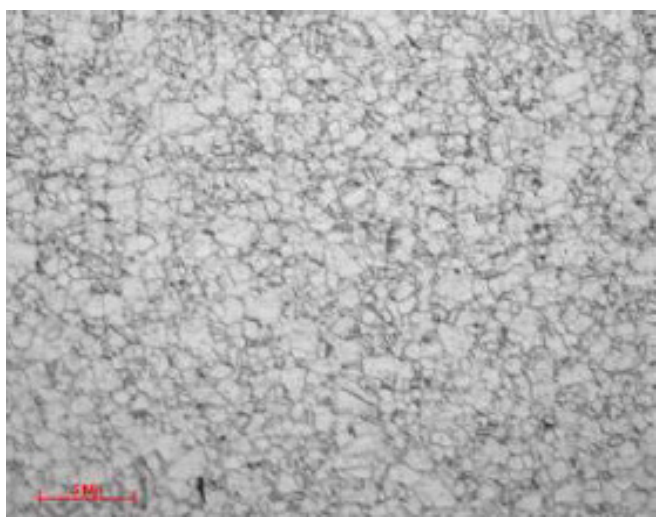

Figure 4. The Rene 88 disk forging exhibited a uniform microstructure after heat treatment.

The ultrasonic response of the forging correlated to the billet testing, high noise areas were detected which is most likely the result of a remnant billet conversion pattern. The grain size differential which influences the ultrasonic noise at this level is not detectable on routine macro-etch operations. No indications were detected.

The disk was machined and subsequently cut into sections for mechanical property testing. Tensile test results obtained from the bore, web and mid-radius sections of the disk were uniform. In addition, radial and tangential testing indicated that the mechanical property response was independent of grain flow in the disk. Tensile property response for Rene 88 is presented in Table II.

Table II. The Rene 88 disk exhibited property uniformity from bore to rim and in both radial and tangential directions.

$\begin{array}{lccccc}\text { Location } & \begin{array}{c}\text { Temp. } \\ \left({ }^{\circ} \mathbf{C}\right)\end{array} & \begin{array}{c}\text { UTS } \\ (\mathbf{M P a})\end{array} & \begin{array}{c}\mathbf{0 . 2 \%} \\ \text { YS } \\ (\mathbf{M P a})\end{array} & \begin{array}{c}\text { Elong. } \\ (\mathbf{\%})\end{array} & \begin{array}{c}\text { RA } \\ (\%)\end{array} \\ \text { Bore (Tangential) } & 204 & 1510 & 1014 & 14 & 18 \\ \text { Web (Tangential) } & 204 & 1503 & 993 & 13 & 17 \\ \text { Rim (Tangential) } & 204 & 1510 & 993 & 15 & 19 \\ \text { Bore (Tangential) } & 399 & 1510 & 983 & 18 & 20 \\ \text { Web (Tangential) } & 399 & 1475 & 972 & 20 & 23 \\ \text { Rim (Tangential) } & 399 & 1482 & 972 & 17 & 22 \\ \text { Radial (Rim) } & 399 & 1475 & 972 & 19 & 21 \\ \text { Tangential (Rim) } & 399 & 1482 & 972 & 17 & 22 \\ \text { Radial (Rim) } & 649 & 1427 & 903 & 18 & 22 \\ \text { Tangential (Rim) } & 649 & 1413 & 945 & 15 & 19\end{array}$


Creep and creep rupture response was evaluated. As indicated in Figure 5, the creep and rupture response for the disk was consistent. Ductilities for all rupture samples tested to failure exceeded $5 \%$.

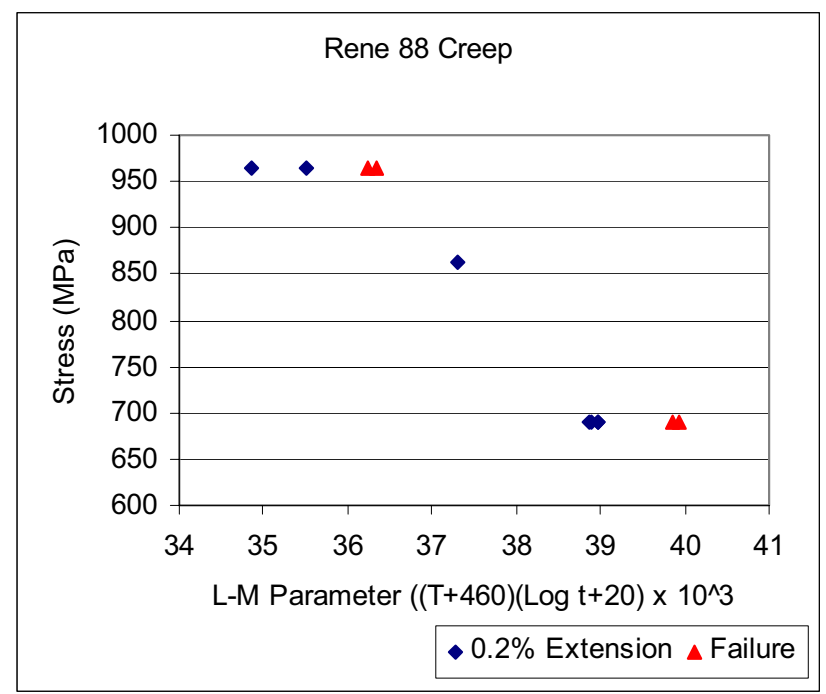

Figure 5. Creep response after forging was consistent in the Rene 88 isothermally forged disk.

The RR1000 billet material was forged into a coverplate configuration similar to a previously produced / evaluated application. The component is forged using an isothermal practice and flat die tooling ${ }^{4}$ to a nominal size of 24 " OD $\times 2$ 1/4" thick. Forging operations were performed in the subsolvus temperature range using standard practices established with larger diameter billet for the production demonstrator shape. Heat treatment was accomplished using subsolvus solution cycle and rapid cooling using the Ladish SuperCooler process ${ }^{5}$ followed by $760^{\circ} \mathrm{C}$ aging practice.

The center slug of the forging was removed for macrostructural evaluations. As indicated in Figure 6, the forge and heat treated macrostructure was extremely uniform from center to edge with no evidence of critical grain growth.

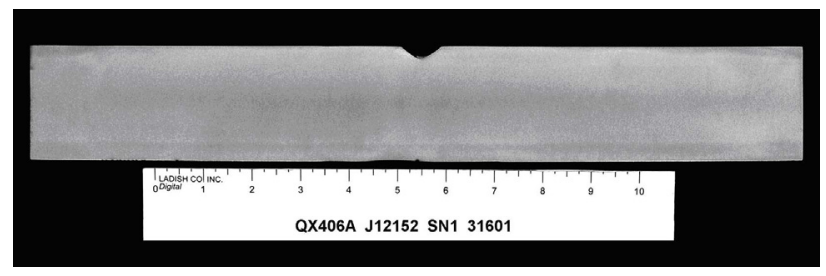

Figure 6. Macroetch of the forging center section did not reveal any evidence of critical grain growth.

The forging was machined after heat treat. Metallographic evaluations were performed at multiple locations on the surface of the ring shape. As indicated in Table III, the average grain size was an ASTM 7-9 with grains as large as (ALA) of ASTM
4. As indicated in Table III and Figure 7, uniformity around the surface of the ring was within one ASTM grain size number.

Table III. Microstructure on the forged coverplate was uniform after heat treatment.

\begin{tabular}{|l|c|c|}
\hline Location & $\begin{array}{c}\text { Average } \\
(\text { ASTM })\end{array}$ & $\begin{array}{c}\text { ALA } \\
(\text { ASTM })\end{array}$ \\
\hline Face, $0^{\circ}$ Position & 7 & 4 \\
\hline Face, $120^{\circ}$ Position & 7 & 4 \\
\hline Face, $240^{\circ}$ Position & 8 & 5 \\
\hline OD, Near-Top & 7 & 5 \\
\hline OD, Mid-Thickness & 9 & 6 \\
\hline OD, Near-Bottom & 7 & 4 \\
\hline
\end{tabular}

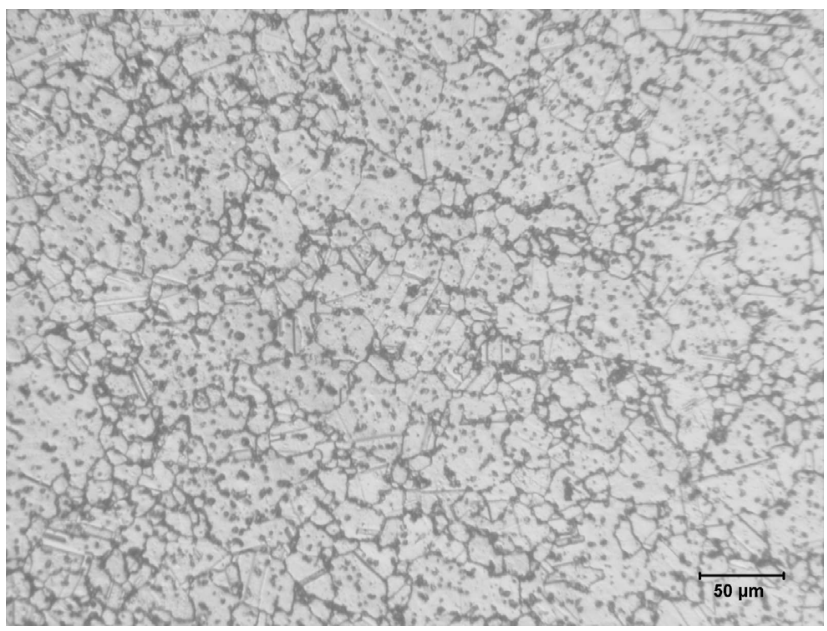

Machined Face $0^{\circ}$ ASTM 7 ALA 4

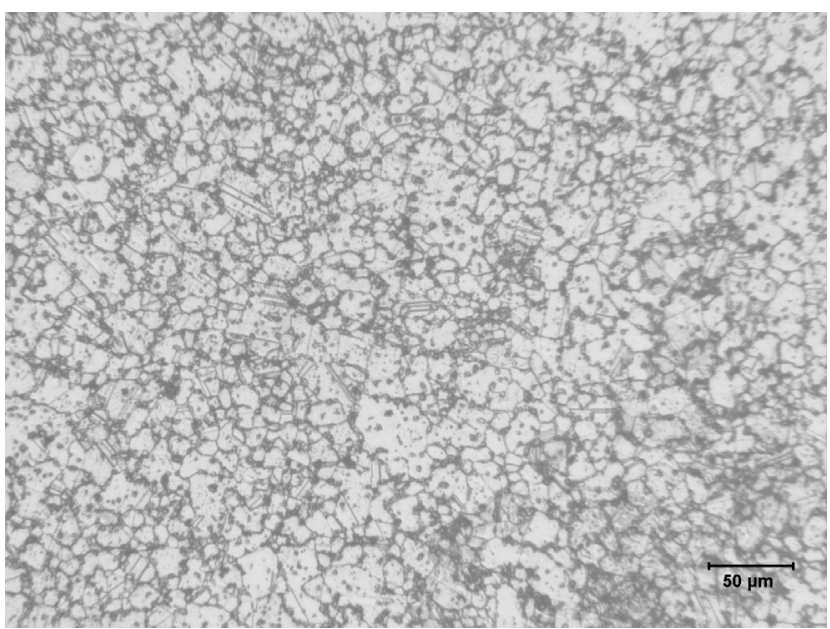

Machined Face $240^{\circ}$ ASTM 8 ALA 5

Figure 7. Grain structure was within one ASTM value and uniform around the surface of the forging. 
The grain size that has been developed from forging and heat treating the SSHIP and press converted billet is significantly larger than the grain size in heat-treated forgings, for which billet was consolidated via the conventional HIP and extrusion route. In such forgings, the average grain size is typically between ASTM 12 to $9(6-16 \mu \mathrm{m})$ after a near-solvus heat treatment (Figure 9 b.). However, it is worth noting that the grain size of HIP and extruded billet material is also finer than that shown here for SSHIP and press converted billet, being around ASTM 14-13 and maybe influencing the recrystallization kinetics of the new process approach.

The micrographs in Figure 9 a) and 9 b) indicate that the specified near-solvus heat treatment has produced primary gamma prime, but this is present in a lower volume fraction than was expected. This suggests that either the starting grain size of the billet or the method of consolidation/conversion appears to have influenced the resulting grain size in heat treated forgings. If the billet grain size is the dominant factor, then the solution treatment temperature can be reduced to achieve a grain size of ASTM 12-9. Unfortunately, this will increase the proportion of primary gamma prime, and may reduce the strengthening potential of the more potent secondary gamma prime on quenching. It is also possible that the ability of primary gamma prime and MC carbide to pin grain boundaries during nearsolvus heat treatment may be different for material that has been forged from conventional HIP and extruded billet to that which has been SSHIP and press converted.

The machined RR1000 coverplate was ultrasonically inspected to production requirements. Ultrasonic inspection met and exceeded specification requirements for HIP plus extruded material. The component was etched and florescent penetrent inspected. Macroetch inspection of the machined component was equivalent to standard forged components produced by isothermal forging from compact plus extruded billet product. No indications were evident during fluorescent penetrant operations.

Test samples were removed from the RR1000 coverplate forging in the tangential orientation after heat treatment. Two tensile specimens and one creep specimen were machined from each quarter. Tensile results, shown in Table IV, show good mechanical property response from the thermal-mechanical processing. The data are considered to be typical of forged RR1000 material that shows an average grain size of ASTM 7.

Table IV. The RR1000 forging exhibited excellent high temperature strength and ductility.

\begin{tabular}{|c|c|c|c|c|}
\hline $\begin{array}{c}\text { Temp. } \\
\left({ }^{\circ} \mathbf{C}\right)\end{array}$ & $\begin{array}{c}\text { UTS } \\
(\mathbf{M P a})\end{array}$ & $\begin{array}{c}\mathbf{0 . 2 \%} \text { YS } \\
(\mathbf{M P a})\end{array}$ & $\begin{array}{c}\text { Elong. } \\
(\%)\end{array}$ & $\begin{array}{c}\text { RA } \\
(\%)\end{array}$ \\
\hline 550 & 1503 & 1000 & 18 & 19 \\
\hline 550 & 1496 & 979 & 19 & 20 \\
\hline 650 & 1420 & 1013 & 20 & 22 \\
\hline 650 & 1406 & 1000 & 22 & 22 \\
\hline 700 & 1255 & 993 & 19 & 20 \\
\hline 700 & 1255 & 993 & 21 & 23 \\
\hline
\end{tabular}

The results of the creep tests are shown in Figure 8. These are consistent with creep strain data that have been generated on fine grain RR1000 material, which has been forged and heat treated from conventional HIP and extruded billet (Figure $9 \mathrm{~b}$.). For such material with an average grain size of ASTM 7 , significantly longer times would have been expected for the specified values of creep strain. However, a super-solvus heat treatment would need to be applied to produce this microstructure, which would show no primary gamma prime.

The data in Tables IV and Figure 8, and the observed grain size and microstructure in Figures 7 and 9 indicate that more work is required to understand the effect of SSHIP and press converted billet on subsequent thermal-mechanical processing. This is important as grain size and the decoration of grain boundaries with primary gamma prime, carbides and borides have a profound influence on the mechanical properties of forged material.

Figure 8. Despite the coarse grain microstructure, creep strain results from disks produced with SSHIP and press converted billet are consistent with data from fine grain RR1000 that has been forged from conventional HIP and extruded billet.

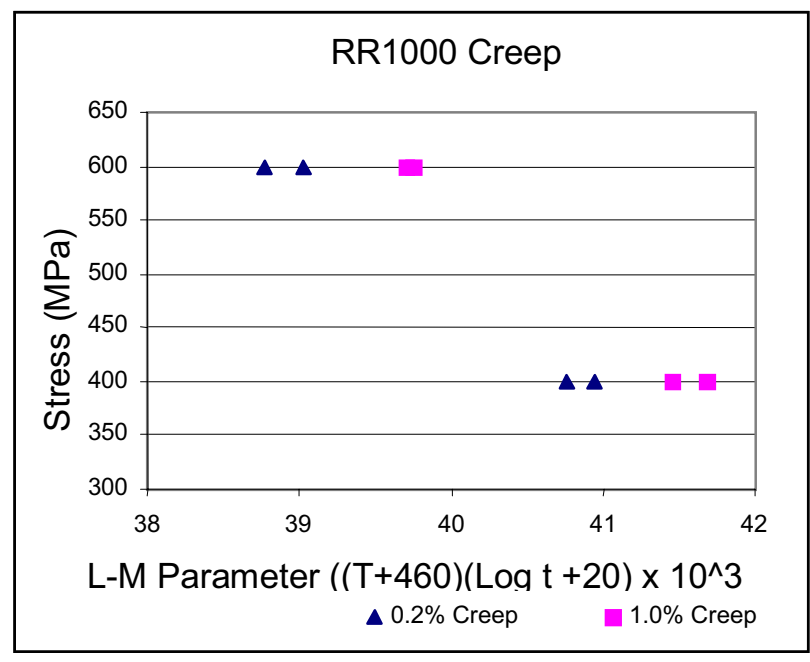

\section{CONCLUSIONS}

The slightly subsolidus hot isostatic pressing of powder metal superalloy in combination with conventional press conversion operations provides an alternative to the hot compact plus extrude practice for producing billet material. In both alloys, the low solvus, high refractory alloy Rene 88 and the high solvus, high temperature alloy RR1000 were converted to fine grain billet without significant cracking or surface degradation. Subsequent isothermal forging of the billet into turbine components from both Rene 88 and RR1000 has shown promising non-destructive and mechanical property capability.

The high ductility of the process route provides the opportunity to utilize new thermomechanical processes and the potential for conventional forging routes for PM alloys. 


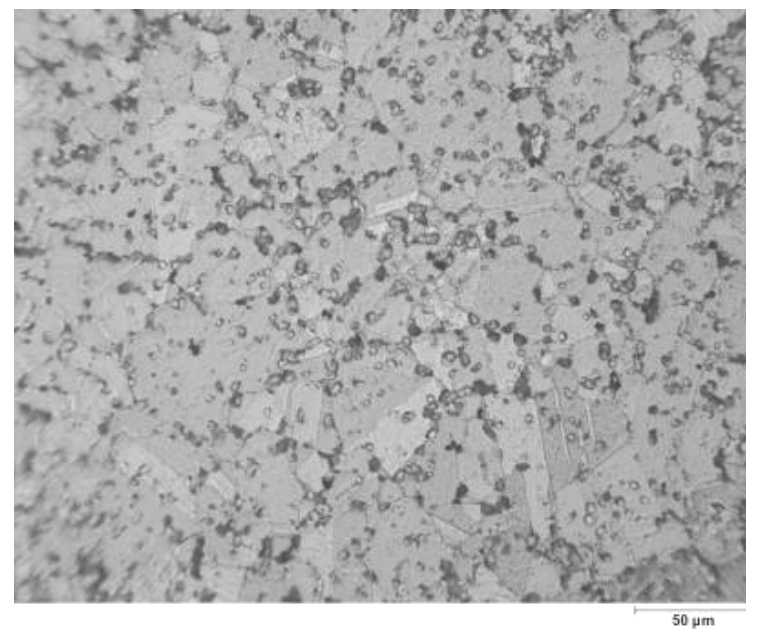

a.) SSHIP + Press Forged RR1000 Heat Treated Disk

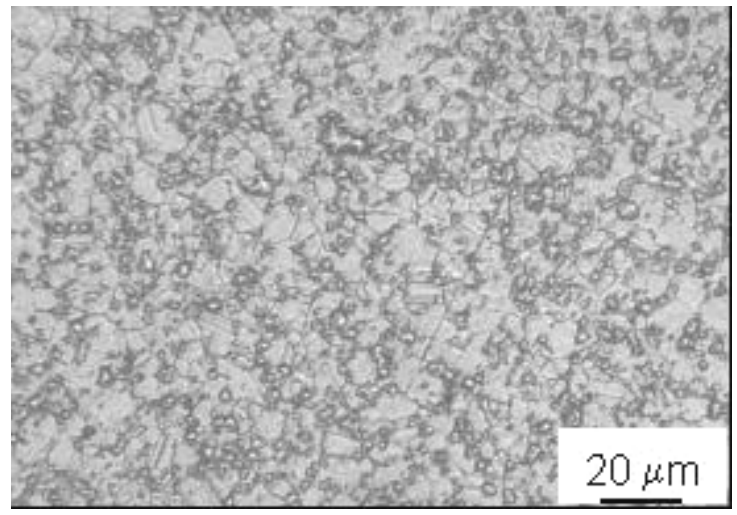

b.) HIP + Extruded RR1000 Heat Treated Disk

Figure 9. The gamma prime distribution in heat treated disks from standard HIP + extrude product and the SSHIP + pressed forged products is slightly different.

\section{ACKNOWLEDGEMENTS}

The authors would like to acknowledge the technical support of Bruce Lindsley and Bruce Antolovich, formerly of Special Metals Corporation for providing the experimental and modeling support. In addition, Joe Lemsky and David Furrer of Ladish Co., Inc. provided technical and operations support in the forging and heat treatment of the two disk components. Randy Helmink of Rolls-Royce provided technical support in the evaluation of the RR1000 forging. Jamie S. Tiley and Walter H. Zimmer of the Air Force Research Laboratories provided technical oversight, program management and support of program activities.

\footnotetext{
${ }^{1}$ B. Antolovich and M. Evans, "Predicting Grain Size Evolution of Udimet ${ }^{\circledR}$ alloy 718 During the "Cogging" Process Through the Use of Numerical Analysis", Superalloys 2000, (Warrendale, PA: TMS 2000), 39-47.

${ }^{2}$ G. E. Maurer, W. Castledine, F. A. Schweizer and S. Mancuso, "Development of HIP Consolidated P/M Superalloys for
}

Conventional Forging Turbine Engine Components", Superalloys 1996, (Warrendale, PA: TMS 1996), 645-652.

${ }^{3}$ E. Huron, S. Srivatsa and E. Raymond, "Control of Grain Size Via Forging Strain Rate Limits for R'88DT”, Superalloys 2000, (Warrendale, PA: TMS 2000), 49-58.

4 J. Lemsky, "HIP+Cog RR1000 Forge Processing Investigation," (Ladish Internal Report XP019 \& QX406, November 20, 2003), 1-7.

${ }^{5}$ US Patent No. 6,304,793, "Method and apparatus of cooling heat-treated work pieces", G. Bunge, Ladish Co., Inc. May 28, 2002.

${ }^{6}$ M.C. Hardy, et al, "Developing Damage Tolerance and Creep Resistance in a High Strength Nickel Alloy for Disc Applications", Superalloys 2004, (Warrendale, PA:TMS 2004) 